\title{
Diffuse Large B Cell Lymphoma: International Prognostic Scoring System Risk Stratification at A Tertiary Care Center in Punjab
}

\author{
Umera Saleem, Rafeeda Maab, Muhammad Asif Naveed, Hajrah Syndeed, Ambareen Hamid
}

\begin{abstract}
OBJECTIVE: To stratify the patients according to international prognostic system and to compare our outcome with international data for Diffuse large B cell lymphoma disease.

METHODOLOGY: It was a descriptive cross sectional study carried out from 2014 to 2018 at Hematology section of Pathology Department, King Edward Medical University, Lahore. Patients were selected by non- randomized purposive sampling. Eighty $(80)$ patients diagnosed by histopathology and immunohistochemistry on lymph node biopsy were enrolled and data was analyzed for qualitative and quantitative variables such as age, gender, B symptoms, type of lymph node and extranodal site involved, complete blood count (CBC), bone marrow examination findings, Ann Arbor stage and serum LDH.

RESULTS: Out of 80 patients, majority were males (51) with M: $F$ ratio of 1.75:1. Median age at diagnosis was $49.5 \pm 16.44$ year. $18.75 \%$ had $B$ symptoms at the time of the diagnosis. Mediastinal involvement was seen in $11.25 \%$ patients while LDH level was elevated in $96.25 \%$. By applying IPSS, $41.25 \%, 23.75 \%$, $\mathbf{2 7 . 5 \%}$ and $\mathbf{7 . 5 \%}$ were categorized into low, low/intermediate, intermediate/high and high risk groups respectively.

CONCLUSION: Majority of our patients presented as Low risk category followed by intermediate/high risk group. High risk group was the least frequently encountered one. The pattern is similar to international data except intermediate/high risk category being the second most common category in our patients.
\end{abstract}

KEY WORDS: Diffuse large B Cell Lymphoma, LDH, IPSS.

This article may be cited as: Saleem U, Maab R, Naveed MA, Syndeed H, Hamid A. Diffuse Large B Cell Lymphoma: International Prognostic Scoring System Risk Stratification at A Tertiary Care Center in Punjab. J Liaquat Uni Med Health Sci. 2019;18(04):290-4. doi: 10.22442/jlumhs.191840645

\section{INTRODUCTION}

There is an upsurge of incidence of Non Hodgkin lymphoma (NHL) worldwide. The commonest sub-type of Non Hodgkin Lymphoma (NHL) is diffuse large $B$ cell lymphoma (DLBCL) ${ }^{1}$ constituting $25-35 \%$ in developed countries. It is also one of the most common lymphoid neoplasms in developing countries ${ }^{2}$.

DLBCL is an aggressive B lymphoid neoplasm ${ }^{3}$. Although DLBCL is potentially curable, management is challenging because of clinical and biological heterogeneity. The outcome of these patients remains variable despite therapeutic advancements with $40 \%$ succumbing to relapsed or refractory disease ${ }^{5}$. Therefore identification of patients unsuitable for standard treatment options is of utmost importance. DLBCL patients are categorized into 4 prognostic groups using International prognostic scoring system (IPSS). Formulated in 1993, IPSS is the most common prognostic tool still today. Its predictive capacity has been validated in multiple studies. It was derived from clinical features of more than 1000 patients with diffuse aggressive lymphomas treated with cyclophosphamide, doxorubicin, vincristine and prednisolone ${ }^{4}$.

The IPSS takes into account five clinical parameters determined at diagnosis: $>60$ year age, advanced stage, raised $L D H$, poor performance status (ECOG $\geq 2$ ) and $\geq 2$ extra nodal site involvement. Based on the number of features, patients were assigned a score and aggregate of scores classifies them into one of four risk groups: Low, Low/Intermediate, Intermediate/ High and High ${ }^{5}$.

For $\leq 60$ years old patients, the prognostic scoring is done by using variables such as High Ann Arbor Stage, high LDH levels and ECOG score of $\geq 2$ into Low, Low/Intermediate, Intermediate/High and High risk groups ${ }^{6}$.

Pakistan is considered to be part of the "lymphoma belt", a region including South Western Asia, Middle East and extending up to North Africa. DLBCL is the commonest reported $\mathrm{NHL}$ in Pakistan ${ }^{7,8}$, but unfortunately significant statistics regarding the clinicopathological presentation of our DLBCL patients have not been evaluated, also there is paucity of data about their IPSS risk stratification. Literature search showed only one study regarding prognostic scoring of aggressive NHLs in one of the major cities, Lahore, 
but the study took into account all the aggressive entities of NHLs collectively and classified the patients into low (0 or 1 risk factor), intermediate (2 risk factors) and high (3 or more risk factors) groups ${ }^{9}$. This prompted us to conduct a study in one of the major referral set ups in Punjab province of Pakistan to generate our data regarding clinicopathological features and risk stratification of our patients of DLBCL and compare the results with international figures.

\section{METHODOLOGY}

This 5 year (2014-2018) cross sectional descriptive study was conducted at Hematology section of Pathology Department, King Edward Medical University, Lahore. Total 80 patients diagnosed with DLBCL on histopathological grounds \& immunohistochemistry were included in the analysis by non-randomized purposive sampling. Biopsy taken from nodal or extranodal sites and immunohistochemical stains included CD10, BCL-6, CD20, CD19, CD22, Ki 67 and Tdt.

The variables of interest computed using SPSS version 23. These included age, gender, B symptoms, mediastinal and bone marrow involvement, LDH levels, performance status and stage of disease.

The internal quality controls were run alongwith patient samples to ensure precision. The samples of $\mathrm{CBC}$ were run on Sysmex $\mathrm{Kx}-21, \mathrm{LDH}$ was analysed on Beckman CX-5 autoanalyser, bone-marrow aspirate was stained by Geimsa and trephine biopsies by H\&E stain.

Prognostic category of each patient was calculated using IPSS and age adjusted International prognostic index (alPI).

\section{RESULTS}

Fifty one out of eighty patients enrolled were males and twenty nine were females (Figure I). M: F ratio was 1.75:1.

\section{FIGURE I: GENDER DISTRIBUTION OF PATIENTS}

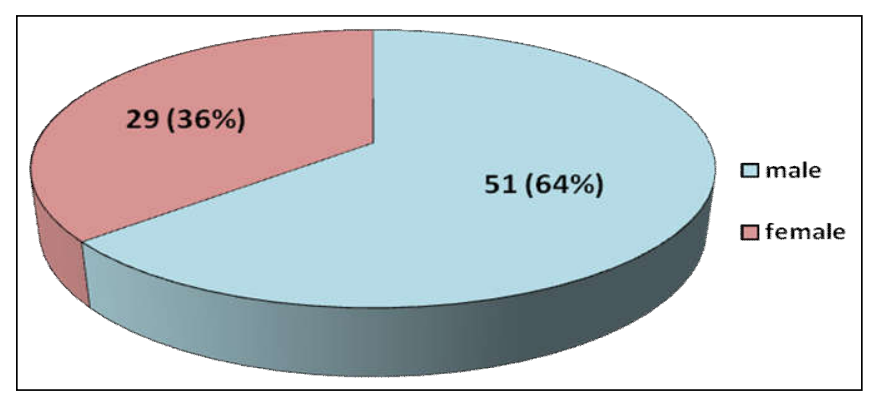

The median age was $49.5 \pm 16.44$ year. LDH level was elevated in $96.25 \%$ of the patients. Mean LDH level was $618.28 \pm 297.2 \mathrm{IU} / \mathrm{L}$. Extranodal involvement was present in $51.2 \%$ and more than 2 extranodal sites were involved in $30 \%$ of our patients. Twenty percent of our patients were found to have an ECOG score of $\geq 2.18$. $75 \%$ of the patients had B symptoms. Mediastinal involvement seen in $11.25 \%$ of the patients. Ten percent of our patients had bulky disease and infiltrated bone marrow.

The most common extranodal site was gastrointestinal tract $(45 \%)$ and cervical lymph nodes were most frequently involved (54\%).

According to Ann Arbor staging, 26 of the patients fell under stage I, 20 belonged to stage II, while 22 and 12 patients were of stage III and IV respectively (Table I).

TABLE I: DISTRIBUTION OF STUDY POPULATION ACCORDING TO ANN ARBOR STAGING

By using IPSS scoring, 33 patients were categorized

\begin{tabular}{|l|c|}
\hline Ann Arbor Stage & $\begin{array}{c}\text { Number and percentage of } \\
\text { patients }\end{array}$ \\
\hline Stage I & $26(32.5 \%)$ \\
\hline Stage II & $20(25 \%)$ \\
\hline Stage III & $22(27.5 \%)$ \\
\hline Stage IV & $12(15 \%)$ \\
\hline
\end{tabular}

low risk, 19 as Low/Intermediate, 22 as intermediate/ high and 06 as high risk (Table II).

TABLE II: RISK STRATIFICATION OF TOTAL SAMPLE SIZE $\mathrm{N}=80$ BY APPLYING IPSS

We calculated the age adjusted international

\begin{tabular}{|l|c|}
\hline IPSS Risk Group & $\begin{array}{c}\text { Number and Percentage of } \\
\text { patients }\end{array}$ \\
\hline Low & $33(41.2 \%)$ \\
\hline Low/Intermediate & $19(23.7 \%)$ \\
\hline Intermediate/High & $22(27.5 \%)$ \\
\hline High & $06(7.5 \%)$ \\
\hline
\end{tabular}

prognostic index (alPI) for patients $\leq 60$ year of age $(n=64)$. Two of these patients were categorized as low risk, 39 as low/intermediate risk, 16 as intermediate/ high risk and 7 as high risk (Table III).

TABLE III: aIPI RISK STRATIFICATION OF PATIENTS $<60$ YEAR $(n=64)$

\begin{tabular}{|l|c|}
\hline \multicolumn{1}{|c|}{ alPI risk group } & $\begin{array}{c}\text { Number and percentage of } \\
\text { patients }\end{array}$ \\
\hline Low & $2(3.1 \%)$ \\
\hline Low/Intermediate & $39(60.9 \%)$ \\
\hline Intermediate/high & $16(25 \%)$ \\
\hline High & $7(11 \%)$ \\
\hline
\end{tabular}


Most of our younger patients fell in low/intermediate risk group and majority of those $>60$ year presented in low risk category. Overall presentation in our patients was early (Figure II).

\section{FIGURE II: COMPARISON OF RISK GROUP STRATIFICATION DEPENDING UPON AGE GROUPS}

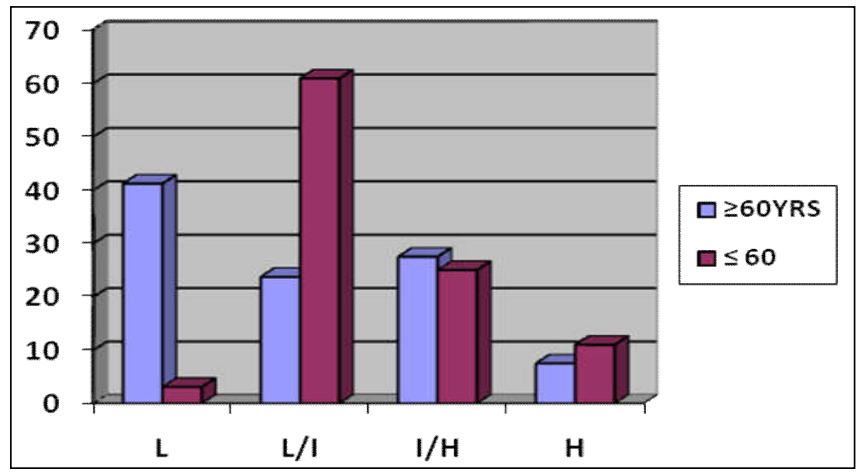

\section{DISCUSSION}

The demographical data of our study showed some variations from the international data available. Median age at diagnosis was $49.5 \pm 16.44$ year ranging from 15 to 75 years. The median age of our patients is considerably lower as compared to western countries but similar to another study from Pakistan (47.2 years) ${ }^{10}$. This difference in age at the time of diagnosis was reported between different regions of the world with median age at diagnosis in western hemisphere to be $7^{\text {th }}$ or $8^{\text {th }}$ decade. In general, underdeveloped and developing countries have a lower age at presentation as compared to developed countries ${ }^{11}$. The difference could, nevertheless, be due to demographic characteristics of developing countries with a lower mean age, lower life expectancy and a greater proportion of young population.

The male predominance in DLBCL patients has been documented by $\mathrm{WHO}^{12}$. Our results also demonstrate the male preponderance in DLBCL $(64 \%)$. This is identical to another study from Pakistan ${ }^{13}$ and comparable to $56 \%$ according to a randomized phase III study from Lysa ${ }^{14}$. M: F ratio of $1.75: 1$ in our study cohort is comparable to the values mentioned in the literature: $1.78: 1^{15}$ and $1.4: 1^{16}$.

Majority of the patients presented in stage I followed by stage III, stage II and stage IV. This pattern of patient presentation is contrasting to western literature where the most frequent stage was stage IV followed by stage III, II and II. Advanced stage was seen in $34 \%$ of our patients compared to $68 \%$ in the University of Lowa ${ }^{1}$. The advanced stage migration in western countries can be explained on the basis of inclusion of sophisticated testing such as PET/CT in disease staging compared to developing countries like
Pakistan where facilities of PET scan are confined to limited centers.

By applying IPSS, $41.25 \%$ of our patients were categorized as low risk group, $23.75 \%$ as low/ intermediate group, $27.5 \%$ as intermediate/high risk group and $7.5 \%$ as high risk group. Our results were comparable to a study conducted in Turkey with minor differences ${ }^{18}$. These subtle differences can be attributed to ethnic or racial differences, host susceptibility, environmental factors or prevalence of HIV and EBV infection between populations of different geographical distribution which we couldn't establish in our study.

alPI score also showed variation from international data, with a low score in $64 \%$ of our patients and high in $36 \%$ in contrast to western data showing $40 \%$ and $60 \%$ respectively ${ }^{19}$. Interestingly, LDH elevation was seen in $96.25 \%$ of our patients in contrast to $56 \%$ of the patient with high LDH levels in international data ${ }^{20}$. Bulky disease was seen in $10 \%$ of our patients while it has been reported in $18 \%$ patients in a Chinese study $^{21}$. B symptoms were seen in $18.75 \%$ of our patients which is similar to $19 \%^{22}$

Mediastinum was involved in $11.25 \%$ of our patients. CNS involvement was not seen in any of our patients while another study from Pakistan documents it to be $5 \%{ }^{13}$.

More than 2 extranodal sites were involved in $30 \%$ of our patients which is comparable to a figure of $41 \%{ }^{1}$ from University of Lowa, while other studies have documented that $>2$ extranodal site involvement was seen in $15 \%{ }^{22}$ and $34 \%$ patients ${ }^{23}$.

Bone marrow was infiltrated in $10 \%$ patients. This figure is similar to $9 \%$ in MYC negative DLBCL patients $^{24}$ while in a study of South India, $24 \%$ of the patients had bone marrow involvement ${ }^{25}$. One possible explanation to this difference could be the method of detection of bone marrow involvement. According to recommendations by $\mathrm{WHO}$, using immunohistochemical stains, flow cytometry and molecular genetics, detection rate of subtle involvement can be increased. Due to cost constraints, these ancillary techniques for documenting marrow involvement could not be included in our study. Our percentage of marrow involvement by morphological assessment is consistent with WHO statistics (10-25\%).

Extranodal involvement was present in $51.2 \%$ of our patients. Though different figures have been quoted in literature; $58 \%$ in MYC negative DLBCL patients and $67 \%^{21}$ in MYC positive DLBCL patients, $36 \%$ (NCCN cohort) and 25\% (BCCA cohort), yet our data is accordant to WHO which states that as many as $40 \%$ of these patients have extranodal involvement.

The most common extranodal site in our study was 
gastrointestinal tract $(45 \%)$, followed by spleen $(28 \%)$, tonsils $(24 \%)$ and testes $(3 \%)$. The most common lymph nodes involved in our study were cervical lymph nodes $(54 \%)$, followed by supraclavicular $(25 \%)$, axillary (15\%) and inguinal lymph node regions $(6 \%)$. Literature lacks data on patterns of nodal and extranodal involvement in DLBCL patients.

ECOG score of $\geq 2$ was seen in $20 \%$ of our patients. Our results are identical to $\mathrm{H}$ Wyndham et $\mathrm{al}^{20}$ and comparable to $37 \%$ according to a study conducted at MD Anderson Centre ${ }^{22}$.

This study is one of its kinds to analyze detailed clinicopathological characteristics and prognostic risk scoring of DLBCL patients in a tertiary health care center using IPSS and aIPI risk stratification systems. The weakness of this study is a small sample size and inability to perform immunohistochemistry, flow cytometry or molecular genetic testing for subtle bone marrow involvement and testing for EBV and HIV due to financial constraints. However careful assessment of bone marrow involvement on morphological grounds by an expert morphologist is still the gold standard in an era of specialized techniques.

\section{CONCLUSION}

Most of patients presenting with DLBCL in our set up fall into Low risk group followed by Intermediate/High risk group according to IPI risk stratification. High risk group is the least frequently encountered one. Our patients have a combination of younger age at presentation, and an early stage at time of diagnosis but with a high tumor burden as manifested by raised $\mathrm{LDH}$ in majority of our patients. The management strategies should be tailored around the clinicopathological features of the patients as they immensely influences the outcome of the treatment.

Ethical permission: King Edward Medical University letter No. 105/PATH/2014, Dated: 17-06-2014.

Conflict of interest: Authors of the study have no conflict of interest to declare.

Funding: There was no Grant or other financial support for this project.

\section{REFERNCES}

1. Maurer MJ, Jais JP, Ghesquières $H$, Witzig TE, Hong F, Haioun $C$, et al. Personalized risk prediction for event-free survival at 24 months in patients with diffuse large B-cell lymphoma. Am J Hematol. 2015; 91(2): 179-184. doi: 10.1002/ ajh.24223.

2. Perry AM, Diebold J, Nathwani BN, MacLennan $\mathrm{KA}$, Müller-Hermelink HK, Bast $M$, et al. Non-Hodgkin Lymphoma in the developing world: review of 4539 cases from the International
Non-Hodgkin Lymphoma Classification Project. Haematologica. 2016; 101(10): 1244-50.

3. Coleman M, Lammers PE, Ciceri F, Jacobs IA. Role of Rituximab and Rituximab Biosimilars in Diffuse Large B-Cell Lymphoma. Clin Lymphoma Myeloma Leuk. 2016; 16(4): 175-181. doi: 10.1016/j.clml.2016.01.004.

4. Zhou Z, Sehn LH, Rademaker AW, Gordon LI, Lacasce AS, Crosby-Thompson A, et al. An enhanced International Prognostic Index (NCCNIPI) for patients with diffuse large B-cell lymphoma treated in the rituximab era. Blood. 2014; 123(6): 837-42. doi: 10.1182/blood-2013-09-524108.

5. Okosun J, Cwynarski K. Non-Hodgkin lymphoma: high grade. In: Postgraduate Haematology. Oxford, UK: John Wiley \& Sons, Ltd; 2015. p.631650.

6. Vitolo U, Seymour JF, Martelli M, Illerhaus G, Illidge $T$, Zucca E, et al. Extranodal diffuse large $B$ -cell lymphoma (DLBCL) and primary mediastinal B-cell lymphoma: ESMO Clinical Practice Guidelines for diagnosis, treatment and follow-up. Ann Oncol. 2016; 27(suppl 5): v91-v102.

7. Sultan S, Baloch N, Ahmed ZA, Irfan SM, Parveen $\mathrm{S}$. Pattern of bone marrow in Non-Hodgkin's lymphoma classified according to WHO classification: Report of a developing country Pakistan. J Lab Physicians. 2018; 10(1):17-20. doi:10.4103/JLP.JLP_9_17.

8. Shabbir S, Ahmed $\overline{K N}$, Marri M, Mengal M, Jan $\mathrm{MH}$, Jamali MS, et al. Epidemiological features of lymphoma in Pakistan. Pure Appl Biol. 2019; 8(1): 977-993.

9. Aziz Z, Sana S, Saeed S, Akram M. Applicability of international prognostic index in non-Hodgkin's Lymphoma in Pakistan. J Ayub Med Coll Abbottabad. 2004; 16(2): 15-20.

10. Abid MB, Nasim F, Anwar K, Pervez S. Diffuse large $B$ cell lymphoma (DLBCL) in Pakistan: an emerging epidemic? Asian Pac J Cancer Prev. 2005; 6(4): 531-34.

11. Shahid R, Gulzar R, Avesi L, Hassan S, Danish F, Mirza T. Immunohistochemical profile of Hodgkin and Non Hodgkin lymphoma. J Coll Physicians Surg Pak. 2016; 26(2): 103-7. doi: 02.2016/ JCPSP.103107.

12. Gascoyne RD, Campo E, Jaffe ES, Chan WC, Chan JKC, Rosenwald A, et al. Diffuse large B cell lymphoma NOS. In: Swerdlow SH, Campo E, Harris NL, Jaffe ES, Pileri SA, Stein H, Thiele J (eds). WHO classification of tumors of heamatopoietic and lymphoid tissues, revised $4^{\text {th }}$ ed. IARC press.Lyon. 2017; 291-297.

13. Qubtia M, Munawar K, Hamid MA, Badar F, Siddiqui N, Kazmi A, et al. Characteristics and 
outcome of patients with diffuse large B cell lymphoma-treated with chemotherapy or chemo-immunotherapy. J Ayub Med Coll Abbottabad. 2016; 28(2): 254-258.

14. Thieblemont C, Tilly $H$, Gomez da Silva $M$, Casasnovas R, Fruchart C, Morschhauser, F. First Analysis of an International Double-Blind Randomized Phase III Study of Lenalidomide Maintenance in Elderly Patients with DLBCL Treated with R-CHOP in First Line, the Remarc Study from Lysa. Blood. 2016; 128(22), 471. doi: 10.1182/blood.V128.22 .471.471

15. Isikdogan A, Ayyildiz O, Buyukcelik A. Non Hodgekin's Lymphoma in Southeast Turkey: Clinicopathologic features of 490 cases. Ann Hematol. 2004; 83(5): 265-269.

16. Bukhari U, Lateef $F$, Jamal S. Frequency of Subgroups of Diffuse Large B-Cell Lymphoma by Immunohistochemistry. J Liaquat Uni Med Health Sci. 2015; 14(02): 78-82.

17. Xie M, Zhai W, Cheng S, Zhang $\mathrm{H}$, Xie $\mathrm{Y}, \mathrm{He} W$. Predictive value of F-18 FDG PET/CT quantization parameters for progression-free survival in patients with diffuse large B-cell lymphoma. Hematology 2016 Mar; 21(2):99-105. doi: 10.1179/1607845415Y.0000000033.

18. Ozturk E, Ozbalak M, Berk S, Erdogan I, Avsar E, Dolgun $A$, et al. Comparison of International Prognostic index and NCCN-IPI in 324 patients with de novo diffuse large B-cell lymphoma: a multicenter retrospective analysis. Leuk Lymphoma. 2016; 57(5): 1211-4. doi: 10.3109/10428194.2015.1079319.

19. Hamlin PA, Zelenetz AD, Kewalramani T, Qin J, Satagopan JM, Verbel D, et al. Age-adjusted International prognostic index predicts autologous stem cell transplantation outcome for patients with relapsed or primary refractory diffuse large B-cell lymphoma. Blood 2003; 102(6): 1989-96.

20. Fang X, Xiu B, Yang Z, Qiu W, Zhang L, Zhang S, et al. The expression and clinical relevance of PD-1, PD-L1 and TP63 in patients with diffuse large B-cell lymphoma. Medicine (Baltimore). 2017; 96(15): e6398. doi: 10.1097/ MD.0000000000006398.

21. Huang JJ, Xia Y, Wang $Y$, Liu PP, Bi XW, Sun $P$, et al. A comparison of R-EPOCH and R-CHOP as a first line regimen in de novo DLBCL patients with high Ki-67 expression in a single institution. Oncotarget. 2016; 7(27): 41242-41250.

22. Chihara D, Westin JR, Oki Y, Ahmed MA, Do B, Fayad LE, et al. Management strategies and outcomes for very elderly patients with diffuse large B-cell lymphoma. Cancer. 2016; 122(20): 3145-51. doi: 10.1002/cncr.30173.

23. Wilson $\mathrm{WH}$, Jung $\mathrm{SH}$, Porcu $\mathrm{P}$, Hurd $\mathrm{D}$, Johnson $\mathrm{J}$, Martin SE, et al. A cancer and leukemia group $B$ multi-center study of DA-EPOCH-rituximab in untreated diffuse large B-cell lymphoma with analysis of outcome by molecular subtype. Hematologica. 2012; 97(5): 758-65. doi: 10.3324/ haematol.2011.056531.

24. Savage KJ, Johnson NA, Ben-Neriah S, Connors $J M$, Sehn LH, Farinha $P$, et al. MYC gene rearrangements are associated with a poor prognosis in diffuse large B-cell lymphoma patients treated with R-CHOP chemotherapy. Blood. 2009; 114(17): 3533-7. doi: 10.1182/blood2009-05-220095.

25. Pai A, Kannan T, Balambika RG, Vasini V. A study of clinical profile of primary extranodal lymphomas in a tertiary care institute in South India. Indian J Med Pediatr Oncol. 2017; 38(3): 251-5._doi: 10.4103/ijmpo.ijmpo_82_16
AUTHOR AFFILIATION:

Dr. Umera Saleem (Corresponding Author)

Assistant Professor

Department of Pathology

Nishtar Medical University

Multan, Pubjab-Pakistan.

Email: umera_saleem@yahoo.com

\section{Dr. Rafeeda Maab}

Demonstrator, Department of Pathology

King Edward Medical University

Lahore, Punjab-Pakistan.

\section{Dr. Muhammad Asif Naveed}

Assistant Professor, Department of Pathology King Edward Medical University

Lahore, Punjab-Pakistan.

\section{Hajrah Syndeed}

Staff Pathologist

Agha Khan Lab, Lahore, Punjab-Pakistan.

\section{Dr. Ambareen Hamid}

Associate Professor, Department of Pathology

King Edward Medical University

Lahore, Punjab-Pakistan. 